\title{
Negative Changes of the Membrane Capacitance due to Electrogenic Na Transport by the Na,K-ATPase
}

\author{
V. S. SOKOLOV, ${ }^{a}$ A. A. LENZ, ${ }^{a}$ AND H.-J. APELL ${ }^{b}$ \\ ${ }^{a} A$. N. Frumkin Institute of Electrochemistry RAS, 117071, Moscow, Russia \\ ${ }^{b}$ Department of Biology, University of Konstanz, 78457 Konstanz, Germany
}

KEYwORDS: Na,K-ATPase; electrogenicity; capacitance; $\mathrm{Na}^{+}$movements; ion binding

Electrogenic $\mathrm{Na}^{+}$transport was investigated in membrane fragments containing $\mathrm{Na}, \mathrm{K}-\mathrm{ATP}$ ase adsorbed to bilayer lipid membranes (BLM) triggered by fast ATP release from caged ATP. ${ }^{1}$ The influence of voltage on the transport after ATP release was determined as small increments of capacitance and conductance by applying an alternating voltage to the membrane. ${ }^{2}$ An electrogenic $\mathrm{Na}^{+}$transport through a cytoplasmic access channel of the $\mathrm{Na}, \mathrm{K}$-ATPase was detected that disappeared after enzyme phosphorylation, and thus produced a negative capacitance and conductance increments at $\mathrm{Na}^{+}$concentrations below $5 \mathrm{mM}{ }^{3}$ This effect was studied now in more detail by measuring the frequency dependence of the capacitance and conductance increments at different $\mathrm{Na}^{+}$concentrations (FIG. 1). Fitting these data by the sum of Lorentzians allowed the discrimination of the separate steps in $\mathrm{Na}^{+}$transport and the determination of their parameters. ${ }^{4}$

$$
\begin{gathered}
\Delta C=C_{0} \frac{\omega_{0}^{2}}{\omega^{2}+\omega_{0}^{2}}+C_{1} \frac{\omega_{1}^{2}}{\omega^{2}+\omega_{1}^{2}}-C_{2} \frac{\omega_{2}^{2}}{\omega^{2}+\omega_{2}^{2}}+C_{\lim } \\
\Delta G=C_{0} \omega_{0} \frac{\omega^{2}}{\omega^{2}+\omega_{0}^{2}}+C_{1} \omega_{1} \frac{\omega^{2}}{\omega^{2}+\omega_{1}^{2}}-C_{2} \omega_{2} \frac{\omega^{2}}{\omega^{2}+\omega_{2}^{2}}
\end{gathered}
$$

At high $\mathrm{Na}^{+}$concentration the frequency dependence could be fitted by the sum of two Lorentzians with the amplitudes $C_{0}$ and $C_{1}$, and a constant term, $C_{\text {lim }}$. The Lorentzian with the lowest corner frequency $\omega_{0}$ (about $30 \mathrm{~s}^{-1}$ ) corresponds to the

Address for correspondence: Dr. V.S. Sokolov, A.N. Frumkin Institute of Electrochemistry RAS, Leninsky pr., 31, 117071, Moscow, Russia. Voice and fax: +7-095-952-5582.

sokolov@netra.elchem.ac.ru 


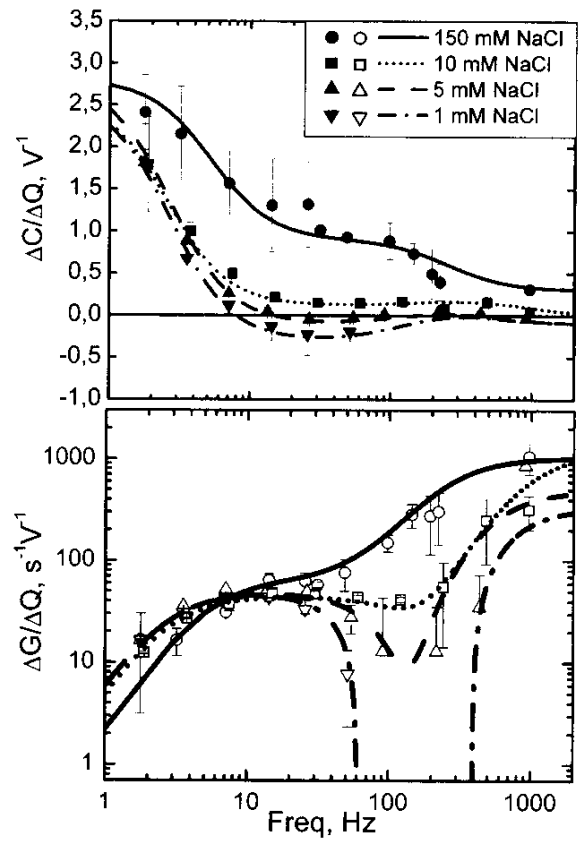

FIGURE 1. Frequency dependencies of capacitance and conductance increments, normalized to the net charge transferred through the membrane after release of ATP from caged-ATP. The solution contained various $\mathrm{Na}^{+}$concentrations (as indicated) and $30 \mathrm{mM}$ imidazole, $10 \mathrm{mM} \mathrm{MgCl}_{2}$, and $1 \mathrm{mM}$ EDTA, $\mathrm{pH}$ 6.5. The lines were plotted according to the Eqs. (1) and (2) using following parameters: $150 \mathrm{mM} \mathrm{NaCl}: C_{0}=1.9 \mathrm{~V}^{-1}, \omega_{0}=33 \mathrm{~s}^{-1}, C_{1}$ $=0.6 \mathrm{~V}^{-1}, \omega_{1}=1600 \mathrm{~s}^{-1}, C_{\lim }=0.3 \mathrm{~V}^{-1} ; 10 \mathrm{mM} \mathrm{NaCl}: C_{0}=2.5 \mathrm{~V}^{-1}, \omega_{0}=16 \mathrm{~s}^{-1}, C_{1}=0.2$ $\mathrm{V}^{-1}, \omega_{1}=6000 \mathrm{~s}^{-1} C_{2}=-0.08 \mathrm{~V}^{-1}, \omega_{2}=1000 \mathrm{~s}^{-1} ; 5 \mathrm{mM} \mathrm{NaCl}: C_{0}=2.9 \mathrm{~V}^{-1}, \omega_{0}=17 \mathrm{~s}-^{-1}$, $C_{1}=0.2 \mathrm{~V}^{-1}, \omega_{1}=3000 \mathrm{~s}^{-1}, C_{\lim }=-0.1 \mathrm{~V}^{-1}, C_{2}=-0.2 \mathrm{~V}^{-1}, \omega_{2}=800 \mathrm{~s}^{-1} ; 1$ mM NaCl: $C_{0}$ $=2.9 \mathrm{~V}^{-1}, \omega_{0}=17 \mathrm{~s}^{-1}, C_{1}=0.2 \mathrm{~V}^{-1}, \omega_{1}=3000 \mathrm{~s}^{-1}, C_{\mathrm{lim}}=-0.1 \mathrm{~V}^{-1}, C_{2}=-0.4 \mathrm{~V}^{-1}, \omega_{2}=$ $800 \mathrm{~s}^{-1}$

slowest step of $\mathrm{Na}^{+}$transport, the conformation transition $\mathrm{E}_{1} / \mathrm{E}_{2}$. The corner frequency coincides with the reciprocal time constant of an exponent decay of the falling phase of the ATP-induced current transient. The Lorentzian with a corner frequency $\omega_{1}$ of about $2000 \mathrm{~s}^{-1}$ corresponds to the "intermediate" step, the release of the third $\mathrm{Na}^{+}$ion through an extracellular access channel. The constant term, $C_{\text {lim }}$, is assigned to the fast $\mathrm{Na}^{+}$ion release through an access channel; its rate could not be resolved so far.

The negative increments at low $\mathrm{Na}^{+}$may be explained by electrogenic $\mathrm{Na}^{+}$transport through a cytoplasmic access channel. This process is suppressed at saturating $\mathrm{Na}^{+}$concentrations. The negative changes depend on frequency, and this dependence can be described by an additional Lorentzian with negative amplitude, $C_{2}$. Its corner frequency, $\omega_{2}$ (about $800 \mathrm{~s}^{-1}$ ), was attributed to the rate of electrogenic $\mathrm{Na}^{+}$transport. The ratio of the "positive" and "negative" Lorentzian, $C_{0} / C_{2}$, is about 10 , and the square root of this ratio, $\sim 3$, gives an estimate of the ratio of the depths of extracellular and cytoplasmic access channels. With the well-documented dielectric depth 
of the extracellular access channel of $0.7-0.75$, the cytoplasmic depth is then calculated about 0.25 .

\section{ACKNOWLEDGMENTS}

This work was supported financially by RFBR No. 01-04-49246 and INTAS (Project 01-0224)

\section{REFERENCES}

1. Borlinghaus, R., H.-J. APell \& P. LäUger. 1987. Fast charge translocations associated with partial reactions of the $\mathrm{Na}, \mathrm{K}$-Pump: I. Current and voltage transients after photochemical release of ATP. J. Membr. Biol. 97: 161-178.

2. Sokolov, V.S., K.V. Pavlov, K.N. Dzhandzhugazyan \& E. Bamberg. 1992. Capacitance and conductivity changes during $\mathrm{Na}^{+}, \mathrm{K}^{+}$-ATPase action in model membrane. Biol. Membr. 6: 1263-1272.

3. Sokolov, V.S., S.M. Stukolov, A.S. Darmostuk \& H.-J. APEll. 1998. Influence of sodium concentration on changes of membrane capacitance associated with the electrogenic ion transport by the Na,K-ATPase. Eur. Biophys. J. 27: 605-617.

4. Sokolov, V.S., A.G. AYUAN \& H.-J. APELl. 2001. Assignment of charge movements to electrogenic reaction steps of the $\mathrm{Na}, \mathrm{K}$-ATPase by analysis of salt effects on the kinetics of charge movements. Eur. Biophys. J. 30: 515-527. 